\title{
Da inovação pedagógica e do papel da tecnologia na educação: algumas considerações possíveis no quadro do Projeto Gilgamesh
}

\author{
Lia Raquel Oliveira*
}

\section{Resumo}

Aprendemos ao longo da nossa vida, inevitavelmente, e a educação deve conduzir ao exercício da cidadania consciente. Mas a escola não detém o monopólio dos saberes necessários. Perante um mundo paradoxal em que o Homo sapiens participa da maior evolução da sua história com algum descaso, dissertamos sobre o problema da doxa, o dos fins da educação, o problema de como e onde ocorre a aprendizagem, e o problema da inovação. Como intenção última, mas de forma brevíssima, colocamos a atual questão dos Recursos Educativos Digitais (RED), no quadro do currículo.

Palavras-chave: Homo sapiens; Projeto Gilgamesh; Recursos educativos digitais.

\footnotetext{
* Docente no Departamento de Estudos Curriculares e Tecnologia Educativa do Instituto de Educação da Universidade do Minho e investigadora no Centro de Investigação em Educação (CIEd). Tem trabalhado na formação de professores e de educadores, com foco em metodologias ativas, conteúdos educativos, laboratórios virtuais, e-portefólios, podcasting, cinema/video educativo e videojogos. Tem ainda produzido investigação no quadro da Pedagogia Universitária. Atualmente, interessa-se pela temática dos usos dos artefatos tecnológicos, sobretudo as superfícies táteis, e por novas literacias. Lecionou em diversas Licenciaturas em Ensino, leciona na Licenciatura em Educação e em vários cursos de mestrado, em Tecnologia Educativa, em Ensino e em Tecnologia e Arte Digital. E-mail: lia@ie.uminho.pt
} 


\section{Pedagogical Innovation and the role of technology in education: some possible considerations in the context of the Gilgamesh Project}

\section{Abstract}

We inevitably learn throughout our lives, and education must lead to the exercise of conscious citizenship. But the school does not hold the monopoly of the necessary knowledge. Faced with a paradoxical world in which Homo sapiens participates in the greatest evolution of its history with some disregard, we discuss the problem of the doxa, the purpose of education, the problem of how and where learning occurs, and the problem of innovation. As a final intention, but very briefly, we put the current issue of Digital Educational Resources (DER) within the framework of the curriculum.

Key words: Homo sapiens; Gilgamesh Project; Digital Educational Resources.

\section{De la innovación pedagógica y del papel de la tecnología en la educación: algunas consideraciones en el marco del Proyecto Gilgamesh}

\section{Resumen}

Aprendemos a lo largo de nuestra vida, inevitablemente, y la educación debe conducir al ejercicio de la ciudadanía consciente. Pero la escuela no tiene el monopolio de los saberes necesarios. Ante un mundo paradójico en el que Homo sapiens participa en la mayor evolución de su historia con algún descuido, disertamos sobre el problema de la doxa, el de los fines de la educación, el problema de cómo y dónde ocurre el aprendizaje, y el problema de la innovación. Como intención última, pero de forma brevísima, planteamos la actual cuestión de los Recursos Educativos Digitales (RED), en el marco del currículo.

Palavras clave: Homo sapiens; Proyecto Gilgamesh; Recursos Educativos Digitales. 


\section{Introdução}

Iniciamos este texto dissertativo concertando algumas ideias presentes e claramente expressas na chamada para este número temático, da responsabilidade de Carlos Nogueira Fino (cf. Editorial deste número): a colocação da questão da construção do conhecimento pelos educandos superando a doxa, sustentada em Paulo Freire (2010); assumindo que a educação deve seguir o caminho conducente à plena cidadania, através da conscientização, da individualidade dialogante, da autonomia e da criatividade; remetendo para uma conceção de pedagogia que extravasa da sala de aula para o mundo, como lugar onde se vive, e onde aprender é parte intrínseca da vida; sendo esta a senda desejável para a inovação pedagógica.

Temos, portanto, o problema da doxa, o dos fins da educação, o problema de como e onde ocorre a aprendizagem, e o problema da inovação. Seguiremos no discorrer do nosso raciocínio a ordem inversa desta enumeração no sentido de equacionar, como intenção última mas de forma brevíssima, a atual questão dos Recursos Educativos Digitais (RED), no quadro do currículo.

\section{Inquietações sobre os adjacentes possíveis do mundo tal como ele está}

Steven Johnson (2010) apresenta sete fatores que terão condicionado (e continuam a condicionar) a "História Natural da Inovação"1: o adjacente possível; as redes fluidas; a intuição lenta; a serendipidade; o erro; a exaptação; e as plataformas. Centremo-nos no primeiro deles - o adjacente possível — inspirado em Stuart Kauffman (2000 apud JOHNSON, 2010, p. 38-39). O adjacente possível refere-se tanto aos limites quanto às possibilidades de mudança e de inovação em qualquer atividade humana, desde logo a atividade neurológica dos nossos cérebros. Pode ser ilustrado da seguinte forma:

Pensemos nele como numa casa que magicamente se expande a cada porta que se abre. Começamos numa sala que tem quatro portas, conduzindo cada uma delas a uma nova sala onde ainda não entramos. Essas quatro salas são o adjacente possível. Mas quando abrimos uma das portas e entramos nessa sala, aparecem três portas novas, cada uma delas conduzindo a uma sala novinha em folha, onde não poderíamos chegar directamente do ponto de partida. (JOHNSON, 2010, p. 39).

Pensado o adjacente possível em termos de educação, temos que qualquer inovação está condicionada por uma miríade de elementos que vai dos próprios indivíduos envolvidos (alunos, professores, gestores, auxiliares, pais, com todas as respetivas particularidades sócioeconómicas, culturais e cognitivas), passando pelos projetos políticos estatais que definem o currículo e a sua operacionalização nos terrenos, pelas condições globais do planeta em que vivemos, até ao conhecimento pedagógico, curricular e didático acumulado.

Dito de outro modo, abrir e/ou fechar portas na procura de novas possibilidades depende das pessoas 'concretas': "Todos vivemos dentro das nossas versões privadas do adjacente possível." (JOHNSON, 2010, p. 48). Ao depender das pessoas depende, também, da sua capacidade de 'jogar o jogo' profissional naqueles terrenos de atuação (por exemplo, os professores nas escolas não podem/devem abdicar da sua autonomia na forma como exercem a docência, desde que de forma justificada e devidamente comprovada com resultados positivos). Depende muito em particular do 'jogo académico', por inerência do jogo político (onde as decisões se processam e ocorrem). O conhecimento acumulado sobre a pedagogia é tão vasto, validado e certificado que os académicos devem assumir a sua responsabilidade: aos académicos da área da educação aplica-se o conceito de "responsabilidade social dos intelectuais" (CHOMSKY, 1998). Como já antes se Ihes aplicava, convenhamos, o conceito de "responsabilidade social do cientista", este introduzido por Norbert Wienner em 1948 (WIENNER, 1961) ao apresentar a soma dos resultados científicos no campo da cibernética e alargando o conceito de comunicação ao domínio da análise e da acção política e social.

Não formular certas questões é extremamente perigoso, mais do que deixar de responder às questões que já figuram na agenda oficial; ao passo que responder o tipo errado de ques- 
tões com frequência ajuda a desviar os olhos das questões realmente importantes. O preço do silêncio é pago na dura moeda corrente do sofrimento humano. Fazer perguntas certas constitui, afinal, toda a diferença entre sina e destino, entre andar à deriva e viajar. Questionar as premissas supostamente inquestionáveis do nosso modo de vida é provavelmente o serviço mais urgente que devemos prestar aos nossos companheiros humanos e a nós mesmos. (BAUMAN, 1999, ii, apud PARASKEVA; OLIVEIRA, 2008, p. 10)

A exploração dos adjacentes possíveis também depende, em enormíssima medida, da capacidade dos adultos envolvidos nos processos educativos 'abdicarem, responsavelmente, do seu direito (adquirido, diríamos, por 'usucapião') sobre os mais jovens que, de facto, só começam a usufruir dos reais direitos de cidadania quando atingem a maioridade. Quero com isto dizer que os mais diretamente interessados no seu próprio processo educativo não tem voz: quem pergunta às crianças e aos jovens o que desejam para a sua educação e, concretamente, para a sua educação escolar?

Uma associação deste conceito de adjacente possível ao de Zona Proximal de Desenvolvimento de Vigostsky pode ser uma trilha frutuosa a apreciar, considerar e percorrer.

Avancemos para uma outra ideia sobre inovação. "Innovación: Condición sine qua non de la educación. Somos perfectibles, la innovación es la respuesta a la búsqueda de la mejora constante y nos interpela para hacer mejor nuestra tarea" (Anna Forés, autora do livro Neuromitos en Educación, 2017)².

Sim, queremos sempre fazer melhor o nosso trabalho e esse é um nobre ideal. Até aqui nada inquieta, salvo a elementar constatação de que quem faz reconhecidamente melhor nem sempre é por tal reconhecido. Somos 'aperfeiçoáveis'... Buscamos a perfeição? Porquê? E para quê? A obssessão de fazer tudo de forma perfeita designa-se por perfecionismo e é considerada uma patologia; no senso comum é um defeito e não uma qualidade. Porquê então correr atrás da perfeição? Na corrida estará o mérito, dir-se-á: o Homo sapiens é um ser que caminha...

Yuval Noah Harari, académico israelita especialista em História Militar, provoca-nos logo na contracapa do seu último livro Homo Deus: História Breve do Amanhã:

\begin{abstract}
A guerra desapareceu: É mais provável cometer-se suicídio do que morrer num conflito armado. A fome está a desaparecer: É mais alto o risco de obesidade do que de fome. A morte tornou-se um simples problema técnico: Não alcançamos a igualdade - mas estamos perto de alcançar a imortalidade. $O$ que nos reserva o futuro? (HARARI, 2017a, contracapa).
\end{abstract}

Numa primeira leitura, sentimos que algo não bate certo com as narrativas telejornalísticas diárias a que assistimos complacentemente: situações de guerra em longínquas partes do mundo (ou à porta de casa); crises humanitárias brutais onde não há abrigo nem comida nem água; dezenas, centenas, milhares de mortos por malária ou dengue... Mas Harari sustenta-se em factos estatísticos e o seu discurso é lógico: nunca a espécie humana (o Homo sapiens) viveu tão bem e em tão favoráveis condições ao seu melhoramento e aperfeiçoamento. A quase imortalidade está praticamente ao nosso alcance - para alguns de nós, claro!

Em livro anterior - Sapiens. De Animais a Deuses - Harari apresenta, a dada altura, uma imagem de um (desgraçado) ratinho de laboratório com a seguinte legenda:

\footnotetext{
Um rato em cujo dorso cresceu uma 'orelha' de cartilagem de gado bovino. É um eco arrepiante da estátua do homem-leão na gruta de Stadel. Há 30000 anos, os humanos já sonhavam em conjugar diferentes espécies. Hoje, podemos produzir tais quimeras." (HARARI, 2017b, p. 467).
}

Logo adiante, também podemos ver duas pessoas adultas de "mãos dadas [com] os seus braços biónicos (...) operados pelo pensamento" (idem, p. 473). Progressos biomédicos extraordinários que todos admiramos, aplaudimos e esperamos poder um dia, eventualmente, deles vir a usufruir. 
Vivemos hoje durante mais tempo e melhor à custa da domesticação dos outros seres vivos, animais e plantas, e nem paramos para pensar na 'Maior fraude da História', designação usada por Harari (2017b, pp. 99-121) para caracterizar a Revolução Agrícola na história da Humanidade, durante a qual o Homem se terá tornado escravo de si próprio iludindo-se com a diminuição da dificuldade em aceder a alimentos, ou seja, o Homo sapiens preocupa-se com a sua sobrevivência - a sua (e normalmente a da sua prole) - e os Homo sapiens iludem-se a si próprios e enganam-se uns aos outros.

Mais, Harari desassossega-nos cruamente:

Estamos a esforçar-nos por criar a Internet-de-Todas-as-Coisas na esperança de que nos torne mais saudáveis, felizes e poderosos. Porém, assim que a Internet-de-Todas-as-Coisas estiver operacional, podemos passar de criadores a partículas e mais tarde ser transformados em dados, desaparecendo por fim na corrente de dados como um pedaço de terra engolido por um rio transbordante. Deste modo, o Dataísmo ameaça fazer ao Homo sapiens o que este fez a todos os outros animais. (HARARI, 2017a, p. 442)

Ciências biomédicas e ciências informáticas caminham a par, sabemos, e este "tsunami fluvial" não é mais que o culminar da fluidez descrita por Zigmunt Bauman (2001) e que, em muitos aspetos, já atingiu o estado gasoso previsto por Marx e Engels em 1948:

A burguesia não pode existir sem revolucionar continuamente os instrumentos de produção e, por conseguinte, as relações de produção, portanto todo o conjunto das relações sociais. A conservação inalterada do antigo modo de produção era, ao contrário, a primeira condição de existência de todas as classes industriais anteriores. O contínuo revolucionamento [...] da produção, o abalo constante de todas as condições sociais, a incerteza e a agitação eternas distinguem a época burguesa de todas as precedentes. Todas as relações fixas e cristalizadas, com seu séquito de crenças e opiniões tornadas veneráveis pelo tempo, são dissolvidas e as novas envelhecem antes mesmo de se consolidarem. Tudo o que é sólido e estável se volatiliza, tudo o que é sagrado é profanado, e os homens são finalmente obrigados a encarar com sobriedade e sem ilusões sua posição na vida, suas relações recíprocas" (MARX; ENGELS, 1988, p. 69, sublinhado nosso).

Ivan Satuf (2016), pensando o modo de relacionamento dos humanos com as tecnologias digitais, desenvolve um pensamento muito interessante relativamente à metáfora do Ciberespaço e à metáfora da Nuvem: se o ciberespaço pressupunha/pressupõe dois espaços paralelos, o real e o virtual (digital), com situação de 'entrada e saída' num ou noutro, com 'chaves de acesso' que abriam/abrem ou fechavam/fecham, a Nuvem, por seu lado, está 'sempre ali', omnipresente, ubíqua, incorporada (embodied) e aberta a tudo a todos. Ou seja, esta metáfora do ciberespaço já não serve (pelo menos completamente) como lente de análise para o tipo de ambiente tecnológico a que chegamos.

A partir daqui, podemos pensar, se quisermos, em fases do digital: a fase do Digital 1 — sólida, caracterizada pelo disco rígido, pela cópias pessoais, pelo controlo (mesmo que relativo) da informação pessoal e corporativa ou institucional; a fase do Digital 2 - líquida, caracterizada pela expansão dos cabos óticos e dos satélites, por um controlo já ilusório da informação em que as pessoas ainda julgam ser donas do que é seu e se entusiasmam com a possibilidade de serem 'produtoras de informação e conhecimento' (autoras - de direito - de qualquer coisa), glorificando a partilha e a troca; e a fase do Digital 3 - gasosa, caracterizada pela ubiquidade, pela cloud, a computação em nuvem que, em si mesma, encerra um tipo de mentira (pelo menos por omissão) dado que os dados continuam a circular através da atmosfera, via satélite ou ainda cabos. E esses dados não estão em 'nuvem' alguma: os dados estão 'em algum sítio', armazenados (em linguagem binária, como é óbvio) em servidores concretos e de localização mais ou menos pública como se pode ver nas imagens seguintes ( 1 e 2 ). 
Imagem 1 - A "Rede Jupiter do Google conta com um total de 100 mil servidores, como os da foto, localizados no datacenter de Council Blu$\mathrm{ffs}$, no estado de lowa, Estados Unidos

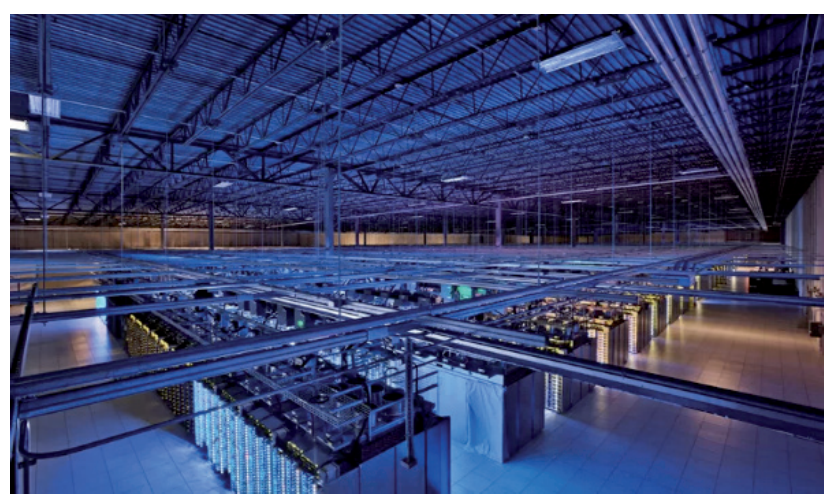

(Foto: Divulgação/Google)" (GARRET, 2017). ${ }^{3}$

Imagem 2 - Interior do prédio que abriga os servidores do Facebook (Redação, 2017)

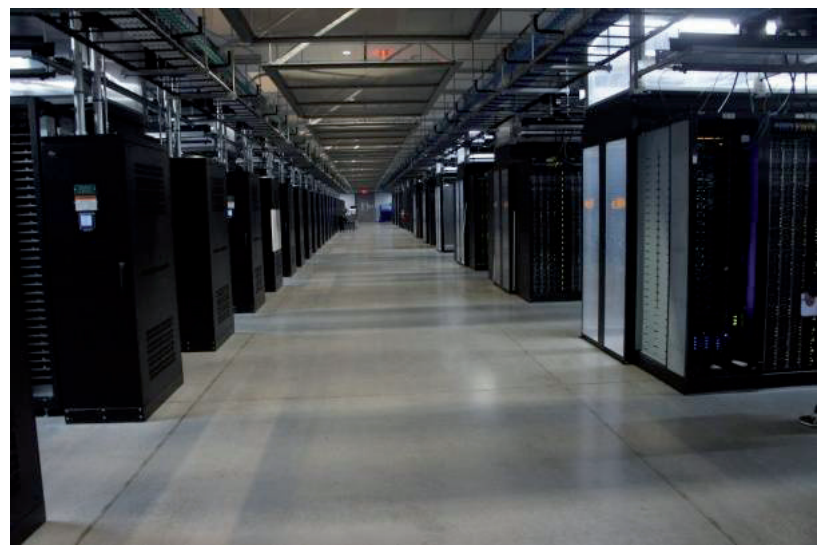

Big Data, analytics, data-mining, computação em nuvem, o entendimento atual da inteligência coletiva que Pierre Lévy imaginou um dia, são os sintomas dessa volatilização. O Dataísmo é apenas uma nova teoria. Sem dúvida. O livro de Harari chama-se Homo Deus, um desenvolvimento do Homo sapiens com uma nova religião chamada Dataísmo.

Dizia Postman (1999, p. 18-19): "somos uma espécie que fabrica deuses [que] autorgam significado às nossas dificuldades, exaltam a nossa história, elucidam sobre o presente e conferem direcção ao nosso futuro".

E outros autores antes (DIONNE; OUELLET, 1990, p. 22): "Os mitos são produto humano, vão-se transformando e a sua força depende de uma fé em alguém. De algum modo, o humano é um vendedor de realidades e as suas relações mediatizam uma perpétua negociação do real". Retomando ainda o raciocínio de Harari (2017a, p. 444)

\begin{abstract}
Contudo, se pensarmos realmente a longo prazo, há três grandes processos ligados entre si que ofuscam todos os outros problemas e progressos: 1. A ciência está a convergir para um dogma abrangente segundo o qual os organismos são algoritmos e a vida consiste no processamento de dados. 2. A inteligência e a consciência estão a seguir caminhos separados. 3. Em brevem alguns algoritmos não conscientes mas de inteligência superior poderão conhecer-nos melhor do que nós próprios.
\end{abstract}

Não há ciência que se faça atualmente sem recurso a meios informáticos: basta pensar na extraordinariamente complexa indústria da publicação científica. Quando o autor separa inteligência de consciência está a falar de inteligência artificial. A consciência é característicamente humana e, para já, irreprodutível. Mas os grandes investimentos em Tecnologia Educativa são dirigidos para as "máquinas de ensinar" (cf. BENJAMIN, 1988; MOEGLIN, 1993), conceito subjacente, subrepticiamente, a toda a atual indústria do ensino privado (a título de exemplo e como é sabido, foi Bill Gates quem financiou a constituição da Khan Academy).

Do que precisamos não é de novas didáticas mas de uma pedagogia que não esteja subordinada ao 'diálogo professor-aluno' e que encare os média como verdadeiras "máquinas de representar" (JACQUINOT, 1993) e verdadeiras "máquinas de comunicar" (PERRIAULT, 1989). Máquinas que nos 'sirvam'!

Edward Hamilton e Andrew Feenberg evocam a discutem as primeiras experiências de ensino online (antes da crise financeira universitária) que cimentaram dois modelos de abordagem: um entendendo o computador como ferramenta de representação, outro entendendo-o como ferramenta de comunicação. $O$ primeiro deles admitindo a tecnologia como um dado adquirido, implicando a 'promoção' dos professores a 'peritos no conteúdo' e, consequentemente, a sua desprofissionalização. Passam estes a ser os os produtores de conhecimento e são sepa- 
rados dos estudantes. Estabelece-se assim um 'modelo de negócio' que permitirá às universidades 'sair da crise'.' (PARASKEVA; OLIVEIRA, 2008, p. 12)

E continua Harari (2017a) de forma quase incomodativa, visto estarmos cientes da iminência de uma qualquer 'singularidade social's (EDEN, et al., 2012) qual a qual teremos de lidar:

Estes três processos levantam consequentemente três questões-chave que espero que permaneçam no seu espírito muito depois de acabar de ler este livro: 1 . Será que os organismos são apenas algoritmos e a vida não é mais do que processamento de dados? 2. O que tem mais valor, a inteligência ou a consciência? 3.0 que acontecerá à sociedade, à política e à vida quotidiana quando os algoritmos não conscientes mas de inteligência superior nos conhecerem melhor do que nós próprios? (HARARI, 2017a, p. 444)

Estas questões ficaram, sem dúvida, no nosso espírito, querendo isto significar que desencadearam no nosso cérebro inúmeras sinapses que estão a influenciar este texto, denotando a complexidade dos problemas abordados e a necessidade e urgência da sua equação. Hoje, o sistema Facebook já sabe muito mais sobre nós próprios do que pensamos! O exemplo mais rudimentar é o dos testes de curiosidades (Qual é a sua alma gémea, Quem seria você numa outra vida, Em que país deveria viver, etc) que operam sobre as informações que postamos e sobre as interações que lá mantemos.

Aliás, parte do sucesso do Facebook (a fofoquice, a troca de historinhas mais ou menos sérias) talvez assente numa dessas pulsões mais fundadoras do Homo sapiens:

A nossa linguagem evolui para nos permitir tagarelar. De acordo com esta teoria o Homo sapiens é, antes de mais, um animal social. A cooperação social é a nossa chave para a sobrevivência e a reprodução. Não basta que homens e mulheres indidividuais conheçam o paradeiro de leões e bisontes. É-lhes muito mais importante saber quem, no seu bando, odeia quem, quem está a dormir com quem, quem é honesto e quem é trapaceiro. (...) Esta teoria pode parecer uma piada, mas é apoiada por numerosos estudos. Mesmo hoje, a grande maioria da comunicação humana - seja sob a forma de e-mails, telefonemas ou artigos de jornais - $\underline{\text { é }}$ composta por mexericos. É tão natural para nós, que parece que a nossa linguagem evoluiu precisamente para isso. (...) [e] Por norma, os mexericos centram-se nas infrações."(HARARI, 2017b, p. 36-37, sublinhados nossos).

São precisamente estas 'trivialidades' (os mexericos), os 'estados de alma', as intimidades, as fotografias, as preferências alimentares e de todo o tipo (os likes - não há ainda hates?), a exibição fácil da geo-localização que, associadas a todo o tipo de pesquisa que realizamos no motor de busca da Google (quem usa motores alternativos?), cruzadas, analisadas, geram a mais valia (valor acrescentado, lucro, e também poder) destas empresas e das empresas associadas.

"Estará a Google a tornar-nos estúpidos?..." "Google is, quite litteraly, in the business of distraction." (CARR, 2010, p. 157). Já não precisamos de nos lembrar de tudo ou, pelo menos, de muita coisa. Sócrates, se fosse vivo, rir-se-ia, por certo! Parafraseando: não vos avisei eu a tempo dos perigos da invenção da escrita?... (cf. PLATÂO, 1981, pp. 120-122, a propósito da invenção da escrita pelo Deus Thoth, na secção Diálogo sobre a Retórica).

A ideia de democracia (aquela associada aos Direitos do Homem e à confiança num Estado representativo eleito de forma séria) está em risco, muitos o denunciam. Muito recentemente, Angela Merkel declarou em noticiários televisivos que o século XX acabou: que já não podemos (a Europa, ou o mundo?...) contar com o Reino Unido nem com os Estados Unidos da América. Há quem sustente, pelo menos em investigações jornalísticas, que os resultados do referendo Brexit e das últimas eleições norte-americanas foram determinados por campanhas fundadas em informações obtidas e detidas pelas empresas em causa ${ }^{7}$. As questões da privacidade e da cidadania que a Internet já gerou transformaram em 'bricadeira real' as campanhas dedicadas às crianças sobre cibersegurança. Todos literalmente adoramos a Internet mas não sabemos como nos defender dela. 
Para milhões de pessoas no mundo inteiro "a Internet é o Facebook" (MIRANI, 2015). Especialmente o Facebook Zero:

Em 2015, pesquisadores avaliando como o Facebook Zero molda o uso da TIC no mundo em desenvolvimento descobriram que $11 \%$ dos indonésios disseram usar o Facebook, os mesmos $11 \%$ também disseram não usar a Internet, $65 \%$ dos nigerianos, $61 \%$ dos indonésios, e $58 \%$ dos indianos concordaram com a afirmação: $\mathrm{O}$ Facebook é a Internet (idem).

Costumamos usar uma expressão humorística:'Felizes os que não tem Facebook'... Paradoxalmente e num outro extremo de usos digitais, o problema é que para pagarmos os nossos impostos temos, obrigatoriamente, de usar a Internet.

Mas o mais curioso e mais espantoso (para uma fã de literatura de ficção científica) em toda esta evolução da nossa espécie é que "ninguém previu a Internet":

Quando teve início a era nuclear, na década de 1940, foram feitas muitas previsões acerca do futuro mundo nuclear do ano 2000. Quando o Sputnik e a Apolo 11 espevitaram a imaginação do mundo, toda a gente começou a prever que, pelo final do século, as pessoas viveriam em colónias espaciais em Marte ou Plutão. Algumas dessas previsões tornaram-se realidade. Por outro lado, ninguém previu a Internet. (HARARI, 2017b, p. 481, sublinhado nosso)

Talvez alguém tenha previsto - provavelmente Ivan Illich em 1971 no seu livro Une Societé sans École (ILLICH, 1971) -, quando concetualizou as suas "quatro redes do saber", no quadro da sua teoria social da educação. Como tivemos ocasião de refletir noutro momento (OLIVEIRA, 2004), tivemos acesso a uma 4a edição do livro que tinha a particularidade de acrescentar ao texto original um apêndice (capítulo 6) cujo objectivo era o de esclarecer alguns possíveis mal-entendidos relativamente a esta sua concepção das "Redes do Saber". Uma alternativa possível à escola basear-se-ia na constituição de quatro redes de serviços de saber que passamos a colocar (ILLI$\mathrm{CH}, 1971$, p. 133-134) e que comentamos. a) "Uma primeira rede encarregue de pôr à disposição do público os 'objectos educativos' (instrumentos, máquinas, aparelhos utilizados para a educação formal)." Os 'nossos' atuais Learning Objects? Recursos Educativos Digitais? Computadores, tablets e smartphones? Quadros interativos? Ambientes virtuais de aprendizagem?...

b) "Uma segunda encarregue da troca de conhecimentos (espécie de base de dados de pessoas desejosas de partilhar as suas competências)". As 'nossas' comunidades de prática e de aprendizagem? As nossa redes sociais?...

c) "Uma terceira rede dedicada a facilitar os encontros entre pares (rede de comunicação temática)". Os 'nossos' grupos de interesse? Os Pinterest's? As videoconferências? O Skype?..

d) "Uma quarta rede dedicada a serviços de referência em matéria de educadores (do género anuário)". Não temos hoje, propriamente dito, 'anuários de educadores' mas temos nos EUA um site já antigo e muito popular chamado Rate My Teacher no qual qualquer pessoa pode colocar as avaliações que entender sobre professores. Em Portugal, por outro lado, proliferam 'Centros de Estudo' para os quais são contratados professores para 'dar explicações' (serviço pago à hora, por sinal, de valor escandalosamente baixo). E existem redes sociais profissionais (e.g. Linkedin)!

Contrariamente ao que por vezes é dito, Illich não preconizava o fim da escola, mas sim uma desescolarização das sociedades: "as escolas são fundamentalmente semelhantes em todos os países, sejam eles fascistas, democráticos, socialistas, pequenos ou grandes, ricos ou pobres" (ILLICH, 1971, p. 126). E continuam sendo. Entendia que a escola possui um programa oculto e secreto, consistindo em convencer as pessoas de que existe um saber que apenas ela detém e que adquiri-lo é imprescindível para o usufruto da cidadania. Este programa oculto 
modifica a concepção que temos de aquisição do saber e transforma uma actividade pessoal numa mercadoria sobre a qual a escola entende ter o monopólio. É a um bem de consumo que damos hoje o nome de "educação; é um produto cujo fabrico é assegurado por uma instituição oficial chamada'escola'. Em consequência, eis-nos mesmo a definir o seu valor pela duração e pelo custo do tratamento aplicado ao estudante. (ILLICH, 1971, p. 192).

Este saber oculto é a doxa, o saber socialmente reconhecido, o saber-coisa ou substância, chancelado pelas Academias e pelos Estados. Agora, será que com a Internet se poderá vir a estabelecer uma nova relação com o saber que questione os fundamentos da doxa (BOULIER, 2000) e que, consequentemente, implique alterações profundas do paradigma vigente (o da aquisição e transmissão do conhecimento) (OLIVEIRA, 2004)?

Por exemplo, e indo buscar uma reflexão anterior (OLIVEIRA, 2008), o construtivismo tornou-se num grande chapéu que tudo abarca e justifica: do ensino assistido por computador tipicamente comportamentalista ao sócio-construtivismo (cf. GIMENO SACRISTÁN, 1982). Os discursos sobre os métodos construtivistas assentam, por norma, na tríade professor-aluno-conhecimento, enformando, portanto, um pré-conceito ao considerarem o conhecimento como autónomo e pré-existente ao ato de conhecer. Também obliteram o facto de o conhecimento oficial, socialmente aceite (a doxa), ser ideologicamente construído, em função dos interesses determinados por minorias dominantes (GIMENO SACRISTÁN, 1982, 2000; APPLE, 1986, 1993; TORRES SANTOMÉ, 2006; PARASKEVA, 2005, 2006, 2008).

Na sua lógica, Illich (1971) utiliza já expressões como "indústria do conhecimento" (p. 84) ou "indústria do saber" (p. 124) e adianta:

A espécie mais perigosa entre os reformadores em matéria de educação é aquela que entende demonstrar que o saber pode ser produzido e vendido de modo bem mais eficaz num mercado livre do que no mercado controlado pela escola. (ILLICH, 1971, p. 203).

E completa, terminando de forma paradoxal:
As garantias constitucionais acordadas à liberdade de palavra, de imprensa, de reunião visavam assegurar uma participação do povo no governo. A electrónica moderna, as imprensas offset, os computadores, os telefones poderiam representar um equipamento capaz de dar um sentido inteiramente novo a estas liberdades. Infelizmente, todas estas conquistas tecnológicas são utilizadas para aumentar o poder dos banqueiros do conhecimento, em vez de servirem para tecer as verdadeiras redes que forneceriam oportunidades iguais de encontro à maioria dos seres humanos. Desescolarizar a estrutura social e cultural exige a utilização da tecnologia para tornar possível uma política de participação (ILLICH, 1971, p. 220, sublinhado nosso).

Sabemos que não podemos prever o futuro (como muito se imagina) porque a tecnologia não é realmente determinista. Enquanto Homo sapiens - com essa capacidade da consciência que ainda não conseguimos replicar - existe 'margem de manobra' para a constituição das nossas práticas sociais. As chamadas novas literacias coisas novas, nunca antes feitas, essas novas práticas sociais significativas associadas aos usos das tecnologias ou resultantes dos usos das tecnologias digitais - serão o quisermos que elas sejam. E constituem um campo aberto para investigações em educação, na tentativa da compreensão do que está a acontecer e pode vir a 'ser': A hipótese das novas literacias (a literacia sendo forma de ler a palavra e o mundo como Ihe chamou Paulo Freire) incorporarem (inserirem no corpo) os artefactos digitais (objetos imateriais produzidos pelo ser humano ) gasosos (estado físico da matéria que não se vê) precisa de ser considerada. Posto que para tal sejam colocadas as questões 'certas'. Qual será a nossa capacidade de influenciar o curso da Internet?...

é ingénuo imaginar que podemos simplesmente parar por completo os projetos científicos que estão a melhorar o Homo sapiens e a transformá-lo numa espécie de ser completamente diferente, pois estes projetos estão inextrincavelmente fundidos com a procura da imortalidade - o Projeto Gilgamesh. Pergunte aos cientistas porque estudam eles o genoma, tentam ligar o cérebro a um computador ou en- 
saiam criar uma mente dentro de um computador. Nove em cada 10 vezes obtém-se a mesma resposta-padrão: estamos a fazê-lo para curar doenças e salvar vidas humanas. (...) É esta a razão pela qual o Projeto Gilgamesh é o navio-almirante da ciência. Serve para justificar tudo o que a ciência faz. O Dr. Frankenstein vai às cavalitas de Gilgamesh. Uma vez que é impossível parar Gilgamesh, também é impossível parar o Dr. Frankenstein. A única coisa que podemos tentar fazer é influenciar a direção tomada. (HARARI, 2017b, p. 482-483, sublinhado nosso).

Tomando emprestadas as palavras de Geneviève Jacquinot-Dealunay num prefácio a um livro (OLIVEIRA, 2004), somos assumidamente não tecnicistas e apoiamo-nos sobre uma conceção vasta da pedagogia enquanto experiência da vida, que é a ocasião (tempo e espaço) da aprendizagem. Não separamos as dimensões subjetiva e objetiva, racional e afetiva (emocional), teórica e prática de qualquer intervenção educativa. É preciso colocar o primado do projeto pedagógico acima de toda e qualquer dimensão, incluindo a técnica porque nunca é pela tecnologia que a inovação chega.

John Dewey (1927) foi bem claro na sua posição sobre a tecnologia e o seu papel no sistema educacional. Para John Dewey (1927), o uso da tecnologia [nas escolas] só tinha sentido se contribuísse para a melhoria da comunicação, diálogo e assim promovesse o interesse público pela política. (...) de que forma podem os mais variados dispositivos tecnológicos (...) ajudar a desnudar a velocidade da informação, comunicação e conhecimento (que tem pautado os nossos dias) e que torna o presente museu?" (PARASKEVA, 2008, p. 26-27).

E quanto aos recursos digitais educativos (REA)? O que são conteúdos educativos?... Integram a equação do 1) currículo prescrito, produzido pelos Ministérios da Educação (para os ensino básico e secundário) e pelos professores universitários (no ensino superior); e do 2) currículo traduzido: os recursos educacionais (recursos isolados, cursos inteiros, disciplinas singulares), 'fechados' ou abertos (open educational resources). E quem 'traduz' estes conteúdos? A indústria da editoras (do tempo dos livros), os professores e os alunos. Estes últimos, infe- lizmente e por norma, ainda por via de processos reprodutivos. Mas os alunos podem e devem ser produtores de conteúdos! Isso não depende do digital! A produção de conteúdos pelos alunos e alunas é justamente a prova, a evidência da sua aprendizagem.

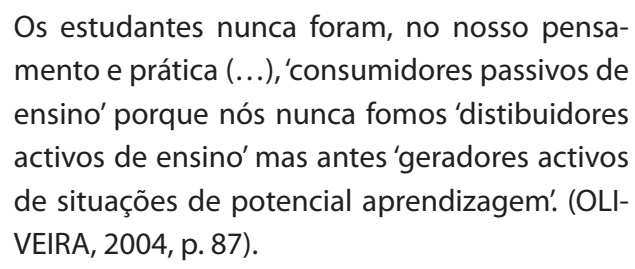

E como podem ou devem ser formulados esses conteúdos, esses recursos? Na imagem 3 temos a mesma história contada de três modos.

Imagem 3 - A História da Carochinha, contada de três modos.
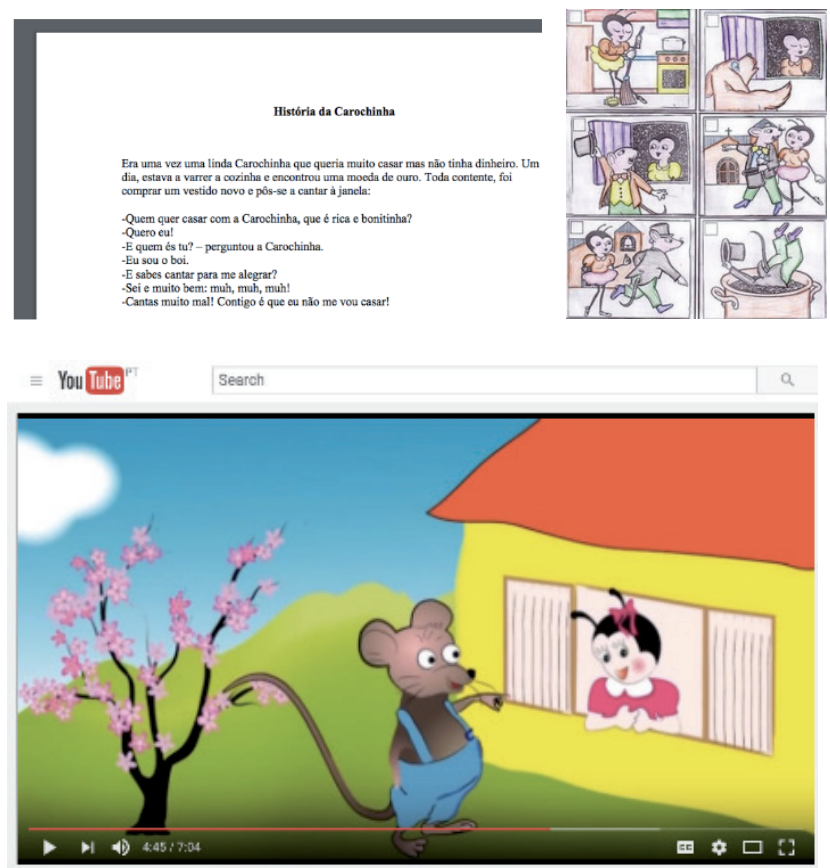

Temos a versão da história em modo texto verbal, em modo desenho (banda desenhada, quadrinhos) e em modo audiovisual (vídeo), e a isto chama-se multimodalidade! Trata-se sem dúvida de modos diferentes mas não são apenas modos diferentes: estão nela envolvidas linguagens diferentes, tecnologias e técnicas diferentes. Não sendo nova a multimodalidade nem o multimédia (que pode ser analógico) são novas - para o storytelling, a arte de contar histórias - as possibilidades de combi- 
nação, de reconfiguração, de apresentação, de construção, de armazenamento e difusão e, sobretudo, de invenção! Temos de convir que, apesar de todos as questões que tratamos acima, o digital facilita a autoria. Terminamos, simbolicamente, com a imagem de um pedaço de um Lenço de Namorados (velha tradição popular portuguesa da região do Minho) pintado (em versão industrializada para consumo mundial e local), à espera de ser manualmente bordado.

Imagem 4 - A esperança na criatividade e no labor.

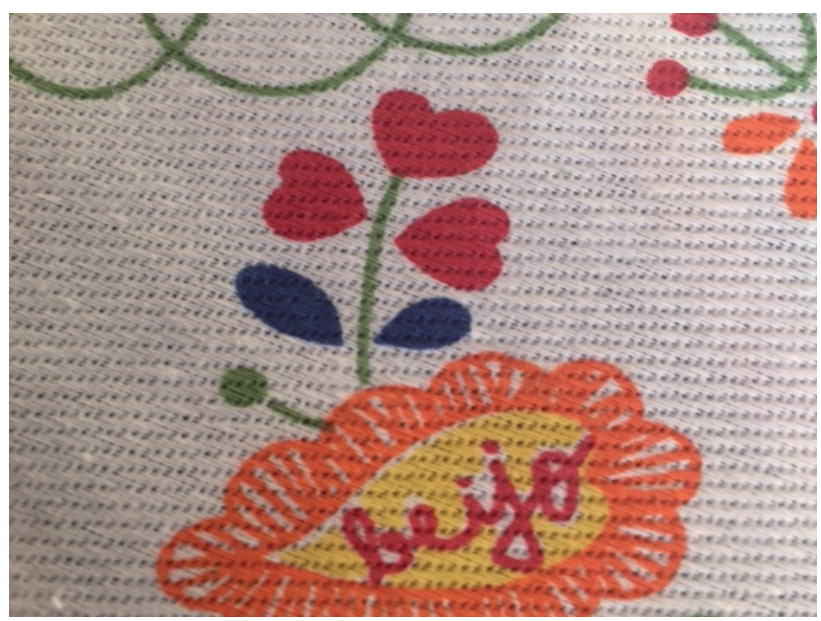

Notas

1 Subtítulo do livro As Ideias que Mudaram o Mundo: a História Natural da Evolução.

2 Anna Forés é autora do interessante livro Neuromitos en Educación: el aprendizaje desde la neurociencia. Esta afirmação consta de uma entrevista à revista online Educación 3.0 (9 de Julho de 2017) http://www.educaciontrespuntocero.com/ entrevistas/anna-fores-vida-aprendizaje/51192.html, acedido a 9 de Agosto de 2017.

3 Fonte da Imagem: http://s2.glbimg.com/4J6I4VKOno5V NJtABQV7FTXXITo=/695x0/s.glbimg.com/po/tt2/f/original/2015/08/20/google-data-center.jpg

4 Fonte da imagem: https://imagens.canaltech.com. br/3263.6048-FacebookDataCenter7.jpg

5 A expressão dos autores referidos é a de "singularidade tecnológica", progressos tecnológicos disruptivos que implicam mudanças sociais radicais. A expressão 'singularidade social' foi usada por Luis Amaral, Professor do Departamento de Sistemas de Informação da Universidade do Minho, numa palestra proferida no âmbito do Seminário de Tecnologia Educativa - Inclusão Digital na Sociedade da Informação, que teve lugar na Casa do Conhecimento de Vila Verde no dia 2 de Junho de 2017. Nesta temática sugere-se a leitura de um artigo jornalístico de Carole Cadwalladr, Are the Robots about to rise? Publicado no The Guardian (https://www.theguardian.com/technology/2014/ feb/22/robots-google-ray-kurzweil-terminator-singularity-artificial-intelligence)

6 Esta questão particular — Is Google Making Us Stupid? What the Internet is doing to our brains - é colocada por Nicholas Carr na revista online The Atlantic, julho/agosto 2008. Disponível em: https://www.theatlantic.com/magazine/archive/2008/07/is-google-making-us-stupid/306868/. Acesso em: 10 ago. 2017.

7 Podem ser consultados vários artigos da já referida jornalista Carole Cadwalladr no site do jornal The Guardian. Um deles: The great British Brexit robbery: how our democracy was hijacked. Sendo certo que, como pode ser verificado na página, o artigo está sob investigação judicial devido a queixas de empresas e organismos citados. Disponível em https://www.theguardian. com/technology/2017/may/07/the-great-british-brexit-robbery-hijacked-democracy. Acesso em: 10 ago. 2017.

\section{Referências}

APPLE, Michael. Official Knowledge. Democratic Education in a Conservative Age. New York: Routledge. 1993.

APPLE, Michael. Teachers and Texts. A Political Economy of Class and Gender Relations in Education. New York: Routledge. 1986.

BAUMAN, Zigmunt. Modernidade Líquida. Rio de Janeiro: Jorge Zahar Editor. 2001.

BAUMAN, Zygmunt. Globalização. As Consequências Humanas. Rio de Janeiro: Jorge Zahar Editores. 1999.

BENJAMIN JR., Ludy T.. A history of teaching machines. American Psychologist, 43(9), 1988. pp.703-712.

BOULIER, Dominique. La loi du support: leçons de trois ans d'enseignement numérique à distance. Les Cahiers du Numérique, L'Université Virtuelle, Volume 1, n² 2. pp.145-172. 2000.

CARR, Nicholas. The Shallows. How the internet is changing the way we think, read and remember. London: Atlantic Books. 2010.

CHOMSKY, Noam. Responsbilités des intellectuels. Marseille: Agone. 1998.

DEWEY, John (1927). The Public and its Problems . Denver: Alan Swallow. 1927.

DIONNE, Pierre; OUELLET, Gilles. La communication interpersonnelle et organisationnelle: I'effet Palo Alto. Québec: Gaëtan Morin Éditeur. 1990. 
EDEN, Amnon H.; MOOR, James H.; SORAKER, Johnny H.; STEINHART, Eric. Singularity Hypotheses: A Scientific and Philosophical Assessment. Berlin: Springer Berlin Heidelberg. 2012

FREIRE, Paulo. Pedagogia do Oprimido [49a Reimpressão]. Rio de Janeiro: Paz e Terra, 2010.

GARRET, Filipe. Google revela bastidores do funcionamento da rede Jupiter. TechTudo. Disponível em: http://www.techtudo. com.br/noticias/noticia/2015/08/google-revela-bastidores-do-funcionamento-da-rede-jupiter.html. Acesso em: 10 ago. 2017.

GIMENO SACRISTÁN, José. A Educação Obrigatória. 0 seu sentido educativo e social. Porto: Porto Editora. 2000;

GIMENO SACRISTÁN, José. La Pedagogia po

r Objetivos: Obsesión por la eficiencia. Madrid: Morata. 1982.

HARARI, Yuval Noah. Homo Deus: História Breve do Amanhã. Amadora: Elsinore, 20/20 Editora, 2017a.

HARARI, Yuval Noah. Sapiens. De Animais a Deuses. História Breve da Humanidade. Amadora: Elsinore, 20/20 Editora, 2017b.

ILLICH, Ivan. Une Société sans école. 4ième édition. Paris: Seuil. 1971

JACQUINOT, Geneviève. Apprivoiser la distance et supprimer l'absence? Ou les défis de la formation à distance. Revue Française de Pédagogie, 102, janvier-février-mars. 1993. p. 55-67.

JACQUINOT, Geneviève. On demande toujours des inventeurs. Communications, 33, 1981. p. 5-23.

JOHNSON, Steven. As ideias que Mudaram o Mundo. A História Natural da Inovação. Lisboa: Clube do Autor. 2010.

KAUFFMAN, Stuart A. O Universo, a Nossa Casa. Lisboa: Bizâncio. 2005.

KAUFFMAN, Stuart A.. Investigations. New York: Oxford University Press. 2000.

MARX, Karl; ENGELS, Friedrich. Manifesto do partido comunista. Petrópolis: Vozes. 1988

MCLUHAN, Marshall. Os Meios de Comunicação como Extensões do Homem. S. Paulo: Cultrix. 1964.

MIRANI, Leo. Millions of Facebook users have no idea they're using the internet. Quartz, February 09. 2015. Disponível em: http://qz.com/333313/milliions-of-facebook-users-have-no-idea-theyre-using-the-internet/. Acesso em: 10 ago. 2017. 2015

MOEGLIN, Pierre. Le paradigme de la machine, à enseigner. Études de communication, 14, 1993. pp. 91-103.

OLIVEIRA, Lia Raquel. A Comunicação Educativa em ambientes Virtuais. Braga: CIEd. 2004.
OLIVEIRA, Lia Raquel. Plano Tecnológico da Educação e Educação Pública: mitos (ensarilhados), limites e falsas promessas. In: PARASKEVA, João Menelau; OLIVEIRA, Lia Raquel (Orgs.). Currículo e Tecnologia Educativa Volume 2. Mangualde: Edições Pedago, 2012. Pp. 165-186.

PARASKEVA, João Menelau; OLIVEIRA, Lia Raquel. Teoria Crítica, Currículo e Tecnologia Educativa. In: PARASKEVA, João Menelau; OLIVEIRA, Lia Raquel (Orgs.). Currículo e Tecnologia Educativa Volume 2. Mangualde: Edições Pedago, 2008. Pp. 7-17.

PARASKEVA, João Menelau. Circunlóquios de Silêncios sobre os Conteúdos Curriculares. In: PARASKEVA, João Menelau; ROSSATTO, C.; ALLEN, R. L. (Orgs.) Reinventar a Pedagogia Crítica. Mangualde: Edições Pedago. 2008. Pp. 89-106.

PARASKEVA, João Menelau. O Presente como Museu. A(s) Tecnologia(s) Educativa(s) como Réu Avant la Lettre. In: PARASKEVA, João Menelau; OLIVEIRA, Lia Raquel (Orgs.). Currículo e Tecnologia Educativa Volume 2. Mangualde: Edições Pedago, 2008. Pp. 19-45.

PARASKEVA, João Menelau. Se a Tecnologia é a Resposta Qual é a Pergunta? In: PARASKEVA, João Menelau; OLIVEIRA, Lia Raquel (Orgs.). Currículo e Tecnologia Educativa Volume 1. Mangualde: Edições Pedago, 2006. Pp. 7-17.

PERRIAULT, Jacques. La logique de I'usage, essai sur les machines à communiquer. Paris: Flammarion. 1989.

PLATÃO. Fedro. Lisboa: Guimarães \& Ca Editores. 1981.

POSTMAN, Neil. El Fin de la Educación. Una nueva definición del valor de la escuela. Barcelona: EUMO Octaedro. 1999.

Redação. Conheça o interior do prédio que abriga os servidores do Facebook. Por Redação| em 21.08.2012 às 12h34. CanalTech. Disponível em: https://canaltech.com.br/redes-sociais/ Conheca-o-interior-do-predio-que-abriga-os-servidores-do-Facebook/. Acesso em: 10 ago. 2017

SATUF, Yvan. (2016). Onde está o ciberespaço? A metáfora da "nuvem" aplicada aos estudos da cibercultura. AÇÃO MIDIÁTICA, n.11. Jan/jun. 2016. Curitiba. PPGCOM-UFPR, pp. 201-220, 2016.

TORRES SANTOMÉ, Jurjo. A Desmotivação dos Professores. Mangualde: Edições Pedago. 2006.

WIENNER, Norbert. Cybernetics: or Control and Communication in the Animal and the Machine. Second Edition. Cambridge: The MIT Press. 1961.

Recebido em 09 de agosto de 2017. Aceito em 01 de setembro de 2017. 